Article

\title{
Integrating Social Innovation into the Curriculum of Higher Education Institutions in Latin America: Insights from the Students4Change Project
}

\author{
Alfonso Unceta ${ }^{1}$, Igone Guerra ${ }^{1, *}$ and Xabier Barandiaran ${ }^{2}$ (D) \\ 1 Sociology 2 Department, University of the Basque Country, 48940 Leioa, Spain; alfonso.unceta@ehu.eus \\ 2 Faculty of Social and Human Sciences, University of Deusto, 20012 San Sebastian, Spain; \\ xabier.barandiaran@deusto.es \\ * Correspondence: iguerra@sinnergiak.org; Tel.: +34-943-018896
}

Citation: Unceta, A.; Guerra, I.; Barandiaran, X. Integrating Social Innovation into the Curriculum of Higher Education Institutions in Latin America: Insights from the Students4Change Project. Sustainability 2021, 13, 5378 https://doi.org/10.3390/su13105378

Academic Editor: Jorge Martin Gutierrez

Received: 5 April 2021

Accepted: 7 May 2021

Published: 11 May 2021

Publisher's Note: MDPI stays neutral with regard to jurisdictional claims in published maps and institutional affiliations.

Copyright: (c) 2021 by the authors. Licensee MDPI, Basel, Switzerland. This article is an open access article distributed under the terms and conditions of the Creative Commons Attribution (CC BY) license (https:// creativecommons.org/licenses/by/ $4.0 /)$.

\begin{abstract}
In the last two decades, social innovation (SI) and social entrepreneurship (SE) have gained relevance and interest within the framework of academia at international level. Higher education institutions (HEIs) are key players in promoting innovation and social entrepreneurship initiatives that respond to multifaceted challenges. They support strategies on the basis of the strengthening of participation, collaboration, and cooperation with society and its local communities. However, the approach of Latin American universities to SI and SE has been very uneven in the way they have understood them, integrated them into academic programmes, and transferred knowledge to society. On the basis of the experience of the Students4Change project, we sought to understand the role of Latin American HEIs in promoting social innovations by analysing the experiences of 10 participating universities to formalise a pedagogical programme on SI and SE in their institutions. The results suggest that there is still a need to formalise an academic syllabus that is specifically designed to promote social innovations and to train universities in this endeavour. This paper contributes to the identification of the main levers of change, strengths, and challenges that Latin American universities face to institutionalise SI and SE in their contexts.
\end{abstract}

Keywords: Students4Change; social innovation; social entrepreneurship; higher education institutions; Latin American universities; academic syllabus; university strategies; Erasmus plus program; social innovation ecosystem

\section{Introduction}

The contemporary political, economic, social, and cultural dynamics transcend national borders and have become global challenges, diverse and complex in nature, requiring, on the one hand, different approaches to how they are tackled, and on the other, the participation of different actors in the design of solutions.

The systems in which we are integrated (health, economy, environment, government, and so on) have seen the emergence of new problems and challenges such as climate change, the loss of biodiversity, transformations in the world of work, high unemployment, or the appearance of new pandemics such as the recent COVID-19, just to mention a few, and have created new areas of vulnerability that require moving away from traditional solutions and opting for innovative solutions. Globality, complexity, vulnerability, uncertainty, and their multicausal nature are all intrinsic characteristics of these contemporary problems. Therefore, these game-changers as defined by Avelino et al. [1] require the adoption of systemic solutions where social innovation is presented as an "umbrella concept" [2] and as a useful vehicle to address these current and future challenges at their roots [3]. Moreover, scholars today agree on the transformative feature of SI itself ([2] and identified it as a tool which helps develop essential mechanisms for systemic change [4]. 
But, as is widely acknowledged, SI as such is not a new concept; indeed, the term with its current meaning was first coined in the 18th century [5]. However, since the end of the 20th century, and in particular since the beginning of the 21st, popularity of the concept, definitions, and perspectives have grown exponentially in Europe and North America. Moreover, it has been the contexts of crisis $(2000,2007,2019)$ which have enabled SI to gain momentum at political, professional, and academic level. Thus, the concept started to gain relevance and to be considered as a new way of creating solutions to address current challenges, visualised more as opportunities than problems by the SI field [2]. In particular, the most recent COVID-19 crisis and the previous financial and economic crisis of 2007 paved the way for the spread of social innovations worldwide.

Some examples of this growing popularity can be found: firstly, in the inauguration of the Office of Social Innovation and Civic Engagement within the Barack Obama administration in 2009, which was created with the aim of bringing citizens and civil society closer to innovative solutions to social problems; secondly, in the emergence of new congresses, such as the International Social Innovation Research Conference (ISIRC) organised from 2009 onwards; thirdly, in the publication of academic articles and specialised reviews such as The Stanford Social Innovation Review; or lastly, in the development of a great number of community-based innovations. In 2010, the European Commission (EU), in its Europe 2020 Strategy, an initiative to build a more inclusive, sustainable, and intelligent economy, had already highlighted the great potential of innovation for the transformation of societies and, in particular, underlined that SI and SE constitute a novel, effective, sustainable and in many cases fair response [6] to address these problems, creating value for society as a whole. Thus, research and knowledge exchange projects, such as CRESSI, SI-DRIVE, SIMPACT, TEPSIE, TRANSIT, SIC, LASIN, SILK, or Students4Change started to be supported and promoted by the European Commission to delve into the concept, dynamics, and impacts of SI [7].

In Latin America, SI has been historically present, although many social innovations, frequently, have not been labelled as such [6]. In many countries of the Latin American region, a wide range of community and socially based initiatives have been promoted, thus supporting the creation of a rich field for experimentation of the development of social innovations. In 2010, the Economic Commission for Latin America and the Caribbean (ECLAC) carried out a first attempt to map SIs in the region and collected a total of 4.800 experiences [8]. SIs, although many of them had a welfare-oriented approach, represented good practices for building alliances and networks between communities, the private sector, and civil society organisations, but had unsignificant social impact due to the weak support that the field of social innovation has received from public bodies. Unfortunately, very often these SI did not end up leading to public programmes and policies [9]. For this reason, this report and subsequent publications on the subject defend the role of academia as a "catalyst for systemic change" and a promoter of strategic relationships around social initiatives which can efficiently and effectively support the identification of solutions which meet the needs of local communities.

\subsection{The Role of Higher Education Institutions (HEIs) in Fostering a Social Innovation Ecosystem}

Social transformations demand a change of mentality, a clean break with the old paradigms, the creation of new ones, and individual behaviour changes, among others. Within this framework, SI plays a central role in the success of these transformations [10] in order to build a more sustainable, resilient, and inclusive society. Universities emerge as the natural space where these paradigms [11] and transformations can be developed [12].

In recent years, HEIs have taken centre stage and have been seen as leading actors to understand social problems, with a high transformative potential to contribute to the sustainable development of our societies through the generation, transfer, and use of knowledge.

The United Nations Educational, Scientific and Cultural Organisation (UNESCO), within the framework of the two world conferences on higher education held in Paris in 
1999 and 2009, recognises, on the one hand, HEIs as key actors in strengthening social, cultural, economic, and political development in our current societies [13]; on the other, it defends the leadership of HEIs in creating worldwide knowledge to address global challenges [14].

Innovation, and by extension SI, are considered essential elements for economic development, social cohesion, and the sustainability of the knowledge society. These are at the forefront of our societies and it is therefore necessary to reinforce our capacities for innovation [15]. Thus, in a knowledge society, academia may have the most important role in the development, testing and dissemination of innovations, including SIs. In this context, HEIs and research institutes represent important platforms to promote intensive exchanges between different disciplines, business sectors and cultures [16].

The 21st century has seen universities questioning their role and transforming and changing their traditional functions. In addition to carrying out their two classic missions (education and scientific research), universities are increasingly developing a third key mission (commitment to society), producing applicable knowledge and promoting innovation, training and retraining qualified professionals, promoting research and business projects, and carrying out territorial development projects in collaboration with other agents in the economic system $[17,18]$.

Regarding SI, its transformative potential $[6,19,20]$ has drawn the growing interest of researchers, policymakers, and practitioners around the world [21], which has provided fertile ground for the study and knowledge surrounding it. Increasing attention has been directed towards conducting, over the second decade of the 21st century, theoretical and empirical research in order to understand the plurality of interactions and relationships that SI reveals from the variety of its spaces of action, influence, and transformation [22,23].

In short, universities play, firstly, a crucial role in conducting research for a better understanding of multi-faceted social problems; secondly, they play an essential role in teaching and building capacities to face these challenges; and finally, they are changemakers by making innovations which should be at the service of the needs of communities.

\subsection{Challenges to Incorporate Social Innovation in Latin American HEIs}

Nowadays, HEIs around the world are facing a major questioning of their teaching and research models. These models do not accurately respond to the social and economic challenges, simply because they have not been prepared for this. Therefore, HEIs should undertake a transformation process to offer proposals of social value of knowledge on the basis of interdisciplinarity and context-related research [24].

Within this framework, a main challenge of HEIs in the region is "linked to the creation of social values oriented to the endogenous local/regional development and sustainable democratic societies" [25]. Thus, the need to transform education systems is highlighted in order to prepare them for the challenges of the 21st century [26].

Overall, HEIs in most Latin American countries are undergoing a process of transformation, and thus they have established some good practices promoting interesting learning experiences. Nevertheless, they will need to go further in this process and focus more on both the competences that the new societal and economic challenges require and the results of the learning themselves [25].

In this endeavour, SI is considered a core strategy to achieve that goal. Specifically, building a SI ecosystem, developing a culture of SI, and fostering research projects on social innovation have been mentioned in 4 of the 12 proposed requirements listed by Didriksson [25], which are as follows:

8. "The construction of a social innovation ecosystem through the structuring of interinstitutional platforms led by knowledge institutions ..."

9. "... All this within the framework of the new autonomy with social responsibility centred on the self-determination of the thought and construction of social innovation".

12. "Articulation between public policies, the development of a social innovation culture in the education system ..." 
14. "The strengthening of the model's level of relevance, which requires a number of conditions, such as the reorientation of knowledge and its scientific, professional and investigative learning towards problem-solving, to organise academic choices in line with the social necessities of the diverse territorial levels and university domains ... the promotion of research projects, social and supportive innovation, as well as the design of pre-professional action research practices, in the service of the community and articulated through real-life scenarios with authentic problems".

Nonetheless, although in recent years academia has played an essential role in promoting SI in the region, scholars in the field recognised that Latin American universities have yet to face the great challenge of embedding this approach into their curricula and that "specific literature on social innovation is still scarce" [6]. Thus, SI initiatives within universities are still silo-thinking and use reductionist approaches that fail to connect the dots. Briefly, three main constraints can be identified within Latin American HEIs.

(a) Lack of a clear understanding about what SI is about.

Awareness and understanding of the "state of the art" of SI have been spurred on by the efforts of public institutions, companies, and academia. This, in turn, has led worldwide to an increased demand for more and better knowledge and research into some concepts related to SI such as social change, sustainability, or the social economy, just to mention a few. In fact, it may be that this richness, based on openness, multidisciplinarity, heterogeneity, and diversity of dynamics and actors, that has made it difficult for the academic community to agree on a definition and a unitary approach to social innovation [24]. Thus, SI is still a concept with a varied spectrum of meanings and approaches [4].

In this sense, although many Latin American HEIs recognise the importance of SI for societal development and the need to be engaged in this area, there is a real need to clarify what social innovation is exactly about [19].

(b) No curricula consensus.

According to Anderson et al. (2014), without a common understanding of what SI is and what it is not, the training content might differ between institutions and, consequently, might result in confusion [27] (p. 12). By the same token, there is no consensus on what the important contents to be taught are, or what the abilities needed to educate social innovators are. Indeed, some scholars hold the idea that the teaching of SE and SI does not necessarily lead to new societally based initiatives or new ventures. Moreover, in the words of many scholars, the teaching of entrepreneurship is negatively correlated with the development of new ventures, and this could be extrapolated [28] (p. 19). Moreover, one of the most important disagreements in terms of curriculum is whether SI and SE should be taught or not. Leaving this point aside, there are three main challenges for integrating SI into the teaching environment in Latin American HIEs: first, defining the competences needed to implement these approaches; second, designing methodologies and methods to guide the learning process; and third, training the teaching staff in social innovation competences.

(c) Little research into SI.

Regarding research into SI in Latin America, this is still germinal and occasional [29]. Issues such as the success factors of SI or its transformative character have scarcely been studied thus far. Therefore, it is still crucial to continue fostering social innovation research in Latin American HEIs in order to establish it as a field of research in its own right [30].

There is definitely an urgent need to create a better understanding SI and its new processes, acquire skills and tools regarding it, and exploit the knowledge coming out of universities more effectively to drive the SI agenda. Latin American HEIs need to have an adequate pedagogy, didactic tools, and trained teachers that support SI learning, an academic model that is not yet developed. This model should involve specific skills, knowledge, behaviours, psychology, and reasoning with trained teachers capable of guiding and mentoring social innovators. 


\subsection{Students4Change Project}

The Students4Change Project (S4C) [31] is a three-year initiative funded under the European Commission's Erasmus+ Capacity Building Programme to integrate SI and SE into the curricula and learning environments at universities in Latin America, improving the quality and relevance of their academic programmes in relation to the knowledge and skills that ought to be developed by students in order to be active players to implement social innovations.

To do this, the project strengthened the SI and SE approaches in the curricula of 10 HEIs in 5 Latin American countries (Brazil, Chile, Colombia, Costa Rica, Mexico) with the aim of building skills in students to become change-makers of social transformations. The consortium of the project was made up of 15 universities: the 10 above-mentioned universities from Latin America, 5 universities from 4 different countries in Europe (Portugal, Spain, France, and Germany), and an NGO. The project started in October 2016 and ended in October 2019.

S4C was structured around seven specific objectives, namely, (1) to implement educational models that promote training in of entrepreneurial and social innovation skills among university students; (2) to offer strategies for teacher training oriented towards developing skills related to social entrepreneurship among students; (3) to design strategies and methodological tools useful to programmes and academic projects (teachers and students involved) to better understand the needs of communities and improve a joint and sustainable resolution of identified problems; (4) to develop a model for monitoring and evaluating the development of social entrepreneurship skills in the curriculum; (5) to design and implement political and institutional processes linked to administrative, academic, and management support in order to promote social innovation in Latin American universities; (6) to establish alliances between Latin American and European universities seeking to promote social entrepreneurship strategies; (7) to strengthen the existing social incubators at participating universities and their links with the student learning process, as well as curricula for generating a better environment for the creation of ideas and improving the efficacy and sustainability of projects.

S4C was developed in three phases as follows:

1. Research. State-of-the-art research into SI and SE in the participating universities.

2. Action. Development of methodologies for entrepreneurship and social innovation, the implementation of the training program, and development of the pilot courses within the 10 Latin American universities.

3. Systemic Change. Assessment of the pilot courses and scaling-up and institutionalising social innovation in each university.

The expected results of the project were

1. To have a common and clear definition of SI and SE in academia.

2. To design a competence-based model to improve SI skills which could be a reference for Latin American universities.

3. To build SI capacities among academic staff by training at least 55 teachers from the 10 participating institutions.

4. To build SI capacities among students by training at least 450 students from the 10 participating institutions.

5. To run 20 pilot courses (two for each university) to improve capacities in SI.

In response to the three steps mentioned above and as a contribution to filling the existing gap of SI in academia, this article has a threefold aim: firstly, it analyses the approach to SI and SE within the participating universities; secondly, it explores the landscape of SI and SE in Latin American HEIs; and finally, it focuses on the enablers and barriers to integrating the social innovation approach into the academic agenda. 


\section{Materials and Methods}

The data used for this article were generated during the course of the S4C project, carried out from October 2016 to October 2019. In this project, a broad approach towards theorising and empirically collecting data on SI within the Latin American HEIs was conducted. The research is based on a descriptive study of the S4C project, which includes a sample of 10 Latin American Higher Education Institutions (see Table 1 below).

Table 1. Latin American participating HEIs.

\begin{tabular}{cc}
\hline Country & Higher Education Institutions \\
\hline Brazil & PUC Rio \\
PUC Rio do Sul \\
\hline Colombia & University of Caldas \\
Uniminuto University \\
\hline Costa Rica & University of Costa Rica \\
Chile & Technologic University of Costa Rica \\
\hline Mexico & University of Talca \\
& PUC Valparaiso \\
\hline Source: authors' & University of Monterrey \\
University of Colima
\end{tabular}

Source: authors' elaboration.

The aim of the research was to learn about the characteristics of the integration of SI in academic syllabuses and to assess the strengths and weaknesses of the incorporation of SI and SE in the curriculum as a result of the implementation of the Students4Change project.

The three main questions which guided the research were as follows:

- Are Latin American universities incorporating SI across their three missions, and if so, what is the prevailing approach to its deployment?

- What are the barriers and enablers for integrating SI into the curricula of Latin American universities?

- How is SI integrated in Latin American universities?

This research exercise was carried out using qualitative methods, considering three sources of data. Firstly, grey literature, made up of around 24 documents and reports generated by the Students4Change project (see Table 2 below), was consulted. The data gathered from the desk-research contained detailed and useful information about the state of the art of SI and SE in the participating HEIs providing a better understanding of the landscape of HEIs in Latin America.

Secondly, data were collected through the participatory observation of the 48 pilot courses run from August 2018 to December 2018 and integrated into individual reports for each pilot course; and thirdly, semi-structured individual interviews were held with students (9) and teachers (29), and focus groups were conducted with academic staff (15), teachers (5), students (24), internal stakeholders (2), and external stakeholders (2). The information obtained from these interviews and focus groups helped us to establish a picture regarding the main barriers and drivers as well as to identify key factors to embed SI into the academic syllabuses of Latin American HEIs.

The choice of interviews and focus groups was made on the basis of stakeholder availability and type during the fieldwork and was carried out by local universities with guidance from the University of the Basque Country.

Bearing in mind that the main purpose of the interviews is to obtain direct information from the agents involved, particularly from teachers and students participating in the pilot courses, the interview tool included questions regarding course planning, competence development, learning outcomes, teaching strategies and assessment techniques, barriers, enablers, and good practices in SI and SE competence development. 
The data from the grey literature, interviews, and focus groups were then triangulated together in order to have a holistic approach. Thus, it was possible to develop a rich understanding of the SI ecosystems in the participating HEIs.

Table 2. Summarised documents from the project.

\begin{tabular}{ccc}
\hline Documents & Type & Year \\
\hline Report of the kick-off meeting of the Students4Change project & Internal Report \\
Report of the consortium meeting in Valencia & Internal Report \\
State of the art of SI and SE in Latin American universities & Internal Report & Manual \\
Toolkit to support SI and SE & Internal Report & 2017 \\
Preliminary draft report from the online training & Internal Report \\
Report of the training course in Porto Alegre & Internal Report \\
Global report of the pilot courses & Internal reports & 2018 \\
Ten individual reports of the pilot courses & EBook & 2018 \\
Social innovation and social entrepreneurship in higher education institutions & Internal Report \\
Report on the support mechanisms in social innovation and social entrepreneurship & Internal Report & 2018 \\
Report on Latin American meeting on social innovation and social entrepreneurship & Report \\
Report of the project cultivarte (Uniminuto) & Internal Report & 2018 \\
External evaluation report (Columbus Association) & EBook & 2019 \\
The university as an agent of change in social innovation and the case of & Students4Change (Puc Río) & 2019 \\
Students4Change final report & Internal report & Document \\
\hline
\end{tabular}

Source: authors' elaboration.

\section{Results}

This section presents the most notable results obtained across the implementation of the S4C project. Results are presented in two subsections according to the landscape of SI and $\mathrm{SE}$ in the participating universities, and quantitative and qualitative results obtained from teaching, research, and community outreach activities.

\subsection{SI and SE in Latin American HEIs}

The project started with a theoretical and empirical collection of definitions, approaches, and dynamics of social innovation within and outside the universities participating in the project. The main objectives were to further develop the concept of SI and SE and also to gain a better understanding of their manifestations in order to design a common pedagogical model.

Consequently, within the framework of the project, an approach to these concepts was built through the analysis of, firstly, the existing literature of reference in the international field; secondly, the results of the collaborative workshop, held within the framework of the kick-off meeting of the project; and finally, the definitions that each university and organisation within the consortium adopts in relation to these two concepts, obtained through an online survey. Thus, the 15 participating institutions analysed how SI and SE were included within their institutions and offered 15 case studies. In order to choose an adequate approach towards SI encompassing the variety of manifestations and understanding from the participating institutions, $\mathrm{S} 4 \mathrm{C}$ selected a relatively open working definition of SI and SE.

In this context, S4C recognised the normative, cultural, and social characteristics behind the diversity of approaches and practices. Thus, in order to have a specific understanding of the term within the framework of the project, the participating universities agreed on a common definition for social innovation and social entrepreneurship, which was as follows:

"Social Innovation is a new solution developed to meet social needs with the objective of generating a social impact or system change wherever they are 
inserted. Social innovations are the result of a broad, diverse and participatory process" [28] (p. 27).

"Social Entrepreneurship is the process of developing mechanisms to create models of sustainable organisations capable of mobilising and integrating resources in order to deliver products or services that generate social value". [28] (p. 29).

As can be identified in these two definitions, SI and SE are two different concepts which are interrelated. It can be stated that the latter is embedded in the former. A notable difference between the two concepts concerns the purpose. While social entrepreneurship focuses on generating social benefits as a result of services, products, or interventions, social innovation pursues a broader outcome. It seeks not only to create social value but also to generate a change in people or communities on the basis of the results of the initiatives. The main elements of each concept are shown in Table 3 below.

Table 3. The main defining elements of SI and SE in the S4C project.

\begin{tabular}{ccc}
\hline & Social Innovation & Social Entrepreneurship \\
\hline What & New solution & A process \\
Objective & Meet social needs & Developing mechanisms to create models of sustainable organisations \\
Purpose & Generate social impact & Generate social value \\
How & Participatory and broad process & Mobilising and integrating resources \\
\hline
\end{tabular}

Source: authors' elaboration.

In parallel to this exercise, S4C developed a mapping of the state of the art of SI in each Latin American participating HEI. We could observe that most of the partners were developing many initiatives in the field of SI and SE, although in some cases these initiatives were not considered as such [28].

Evidence from the project reveals that Latin American HEIs have developed compulsory courses, extra-curricular programmes and a variety of methodologies, teaching and learning tools, and research topics in the field of social innovation and entrepreneurship. In fact, through a questionnaire addressed to the coordinators of the 10 Latin American universities participating in the project, we could identify a total of 48 courses (42 undergraduate and 6 postgraduate) which were framed in various disciplines and areas of knowledge [32], and many of them were taught as voluntary subjects. The multiplicity of areas of study reported could be explained, indeed, by the diversity of definitions and approaches to social innovation and social entrepreneurship within the participating universities, something that according to Galego et al. (2018) [32] could lead to an inadequate classification of the courses.

When we analysed the ways in which Latin American HEIs have related to the communities, we found that in all of them there is the so-called "Social Service", a compulsory pre-graduation programme through which students provide support to the community, which might be an enabler to SI [33].

Some HEIs have created special facilities or centres whose objectives include social entrepreneurship as an ongoing activity, as in the case of PUCRio do Sul or Tecnológico de Monterrey. Other HEIs have gone a step further and have increased social innovation initiatives by strengthening relations with communities by piloting a new pedagogy of teaching and learning, as in the case of Uniminuto, while others have developed grassroots social innovation initiatives by bridging government programmes, community experience, and university knowledge through learning projects, as represented by the University of Talca. Finally, many others have had isolated approaches to SI or have hardly had any at all, exemplified by the case of the university of Colima.

\subsection{Quantitative and Qualitative Results from the Implementation of the Project}

In order to write this section, we analysed two main sources of information: first, quantitative information obtained by the Columbus Association as part of the external 
evaluation of the project, and second, quantitative and qualitative information collected during the evaluation process of the pilot courses by the SC4 consortium.

(A) Teaching activities.

The 10 participating HEIS identified 59 pilot courses and the respective 59 academic syllabuses, led by 57 academics. A complete list of courses is provided in Supplementary File S3.

The distribution of the pilot courses by country gives us the following information: 14 pilot courses were planned to be developed in Colombia, followed by Mexico with 13, Costa Rica and Brazil with 11, and Chile ending the list with 10 (see Figure 1 shown below).

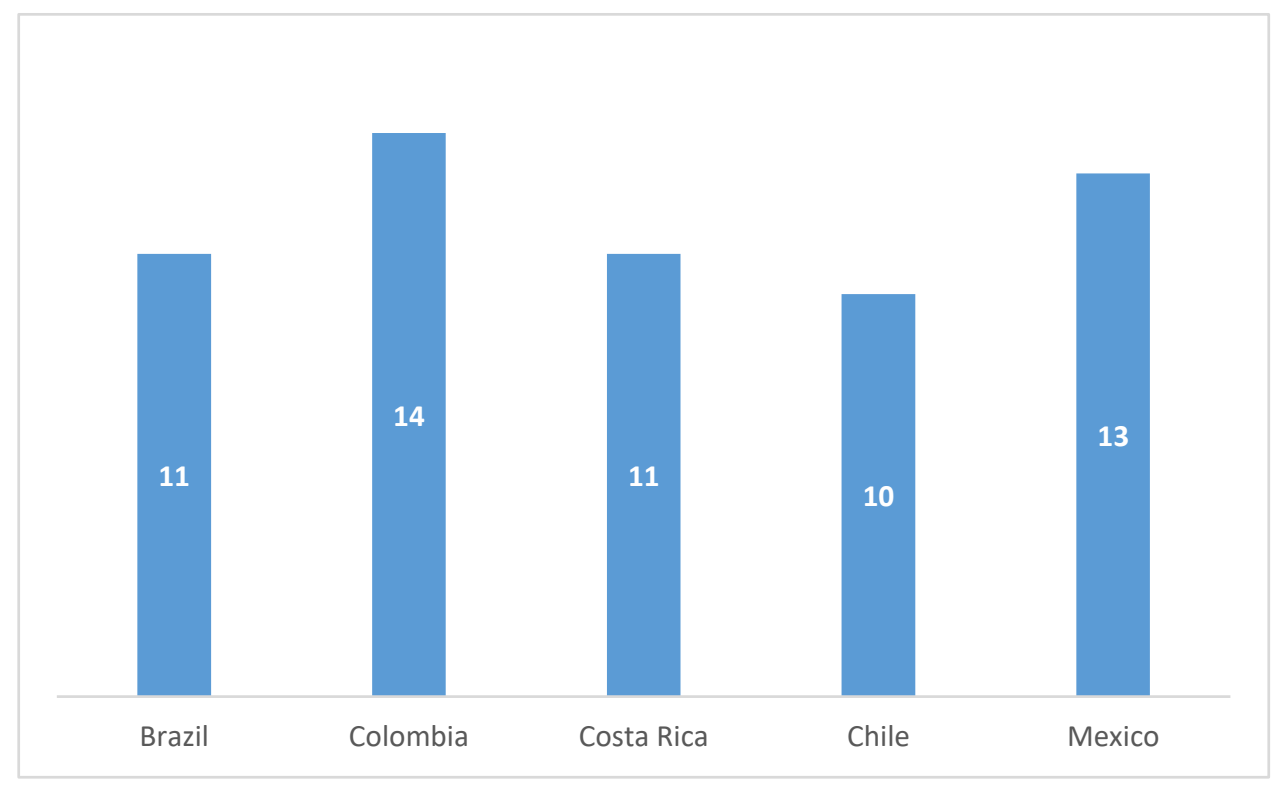

Figure 1. Pilot courses per country. Source: authors' elaboration.

Regarding the field of knowledge of those pilot courses, Figure 2 shown above presents the following data: the largest number of pilot courses fell within the knowledge area of Social Sciences and Law, with a total of 32 in this category. Far behind were the other subject areas as follows: 10 pilot courses belonging to the field of knowledge of Engineering and Architecture, 9 to Arts and Humanities, and 5 to Health Sciences; closing this classification were the only two courses belonging to the area of Science. It is important to note that one of the courses belonged to a non-specific category.

The implementation of the adapted or transformed courses led to approximately 1614 undergraduate students participating. All the courses ran from August 2018 to February 2019; thus, they were applied within an academic semester.

However, according to the external evaluation carried out by the Columbus Association, the 10 Latin American HEIs implemented a total of seventy pilot SI courses, mainly at the undergraduate level. Thus, the project has exceeded the quantitative objectives set at the beginning of the project [34]. Three facts corroborate this statement (see Figure 3): (a) Regarding the number of pilot courses: at the beginning, the project aimed to carry out 20 courses (two per institution); subsequently, after the training course held in April 2018 in Porto Alegre, 59 were identified but 70 courses were finally implemented. (b) Regarding teachers' participation: at the beginning of the project, it was expected that 55 teachers would participate in the project; 56 teachers finally took part in the pilot-courses. (c) Regarding the students: S4C aimed to develop SI competences in at least 450 students from the participating HEIs. The final figure greatly surpassed expectations, with more than 1614 students participating in the different pilot courses. 


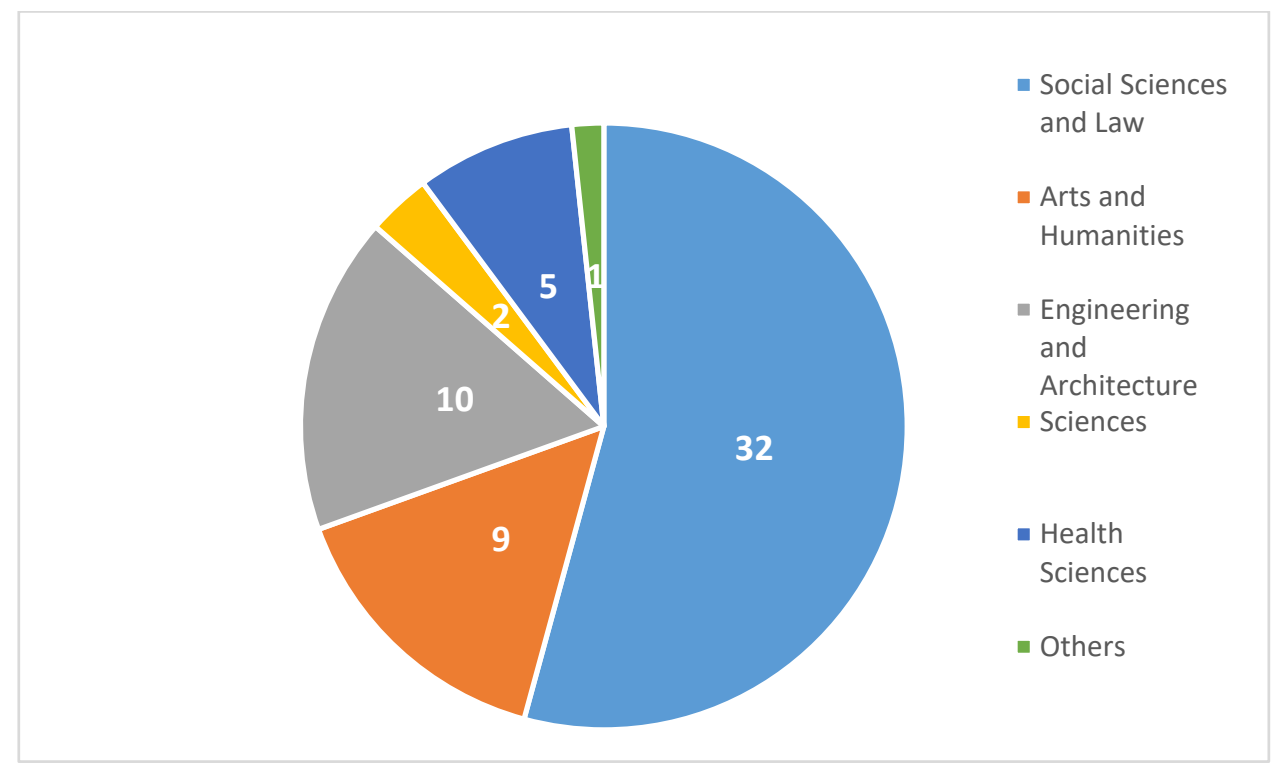

Figure 2. Distribution of the pilot courses per field of knowledge. Source: authors' elaboration.

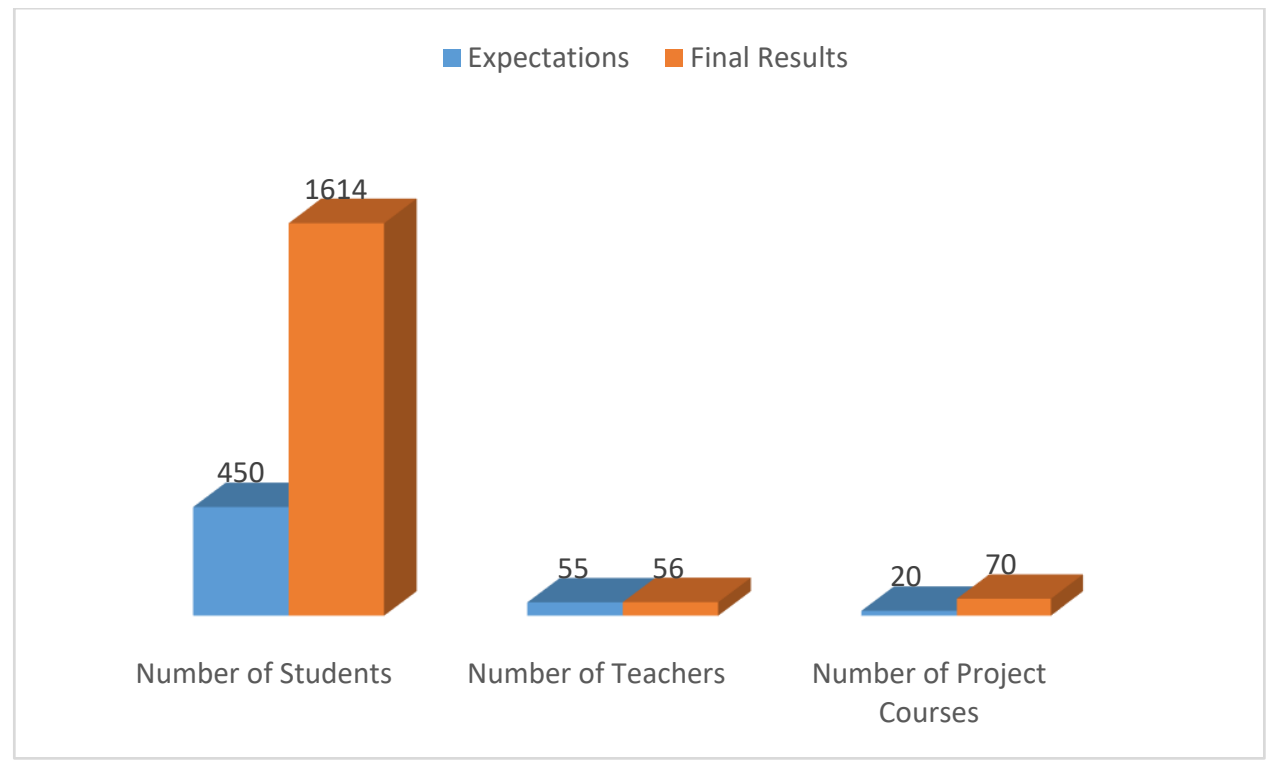

Figure 3. Expectations vs. results. Source: Columbus Association, External Evaluation Final Report, 2019.

Both teachers and students were receptive to the introduction of a new approach. Many results from a survey addressed to teachers (52) and interviews and focus groups with both students and teachers illustrate this statement. Regarding the pedagogical practice, the teachers, as shown in Figure 4, very positively valued the didactic materials prepared within the framework of the project and, in particular, the toolbox, which they consider very useful for the precise and crystal-clear way in which the processes of SI are presented. The opportunities provided by the project to exchange experiences with teachers from other countries as well as the access to advice from experts in the field of social innovation were also highly appreciated. Thus, according to the academic staff, these three dimensions should be taken into account when designing a strategy to incorporate SI into the curricula. 


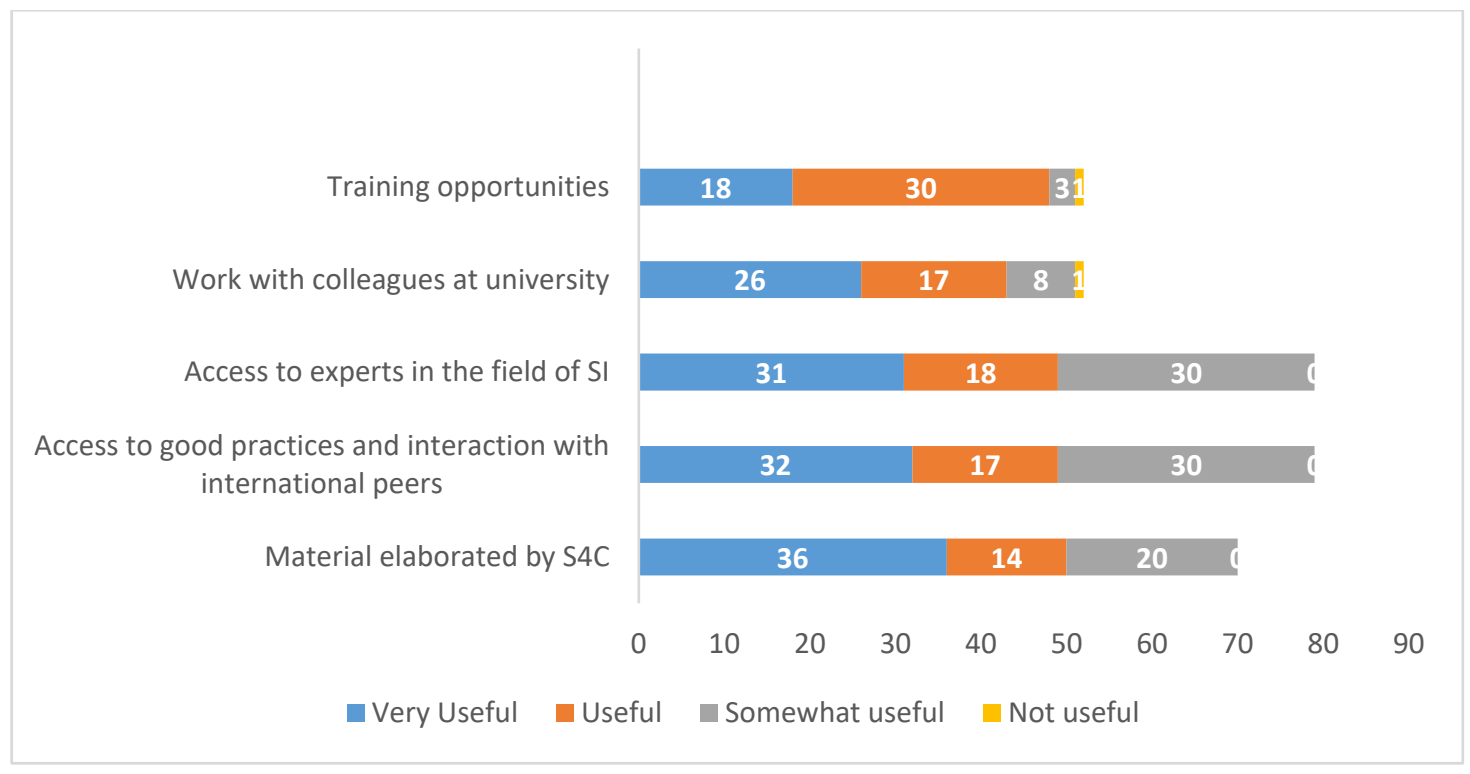

Figure 4. Usefulness of Students4Change project for improving the pedagogical practice. Source: Henao and Samoilovich, 2019.

Taking into account special context features, red tape in universities, and aversion to change, we found that adaptation of the syllabus was one of the main challenges of the project. However, more than half of respondent teachers (37 out of 52) to the survey declared that they could adapt the syllabus to a certain or great extent [34]. Specifically, they stated that they incorporated new tools and didactics into the respective academic syllabuses (51), applied new roles in the class (48), and developed a closer relationship with social actors (46) (see Figure 5 below). The S4C project has demonstrated how students and lecturers can work together in the field of SI.

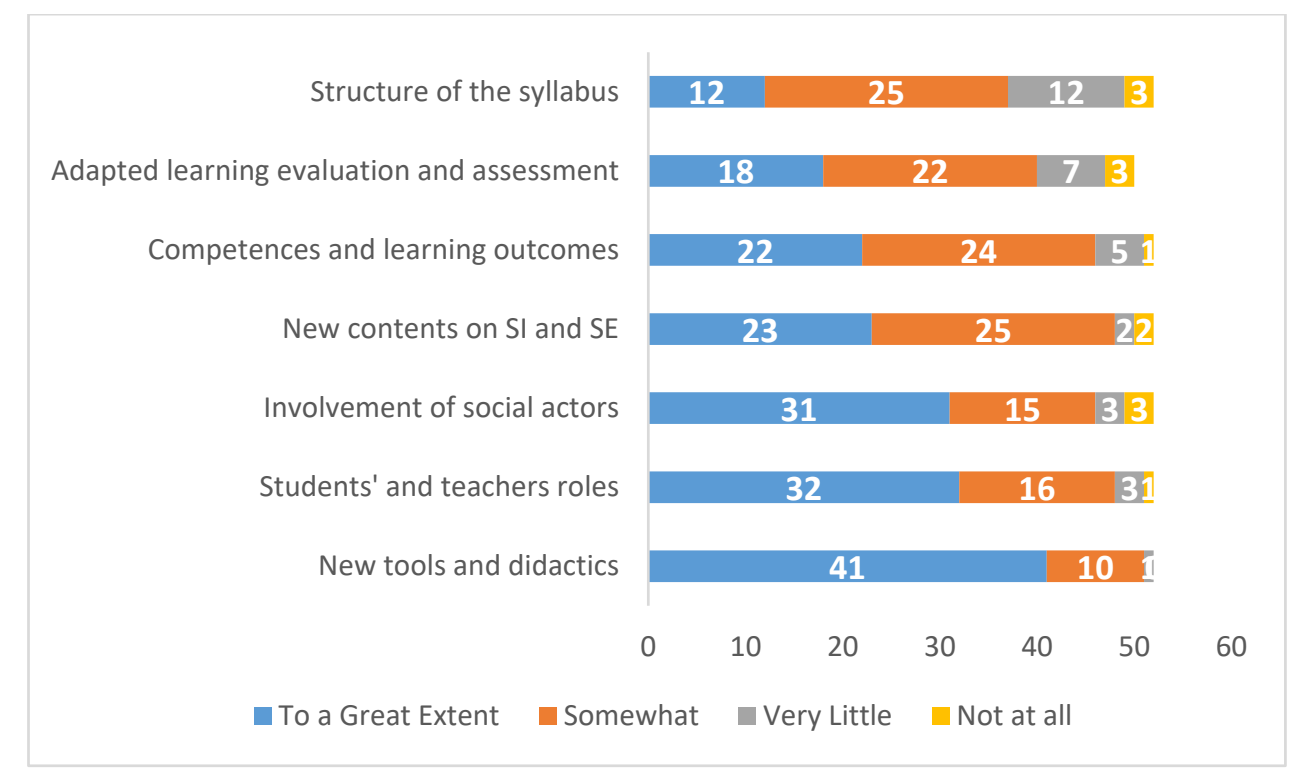

Figure 5. Main curriculum adaptations. Source: Henao and Samoilovich, 2019.

With regard to skills and capacities, both teachers and students considered that the pedagogical model of S4C had a positive effect on the improvement of their technical, functional, and social capacities. Specifically, in the same survey, they highlighted that skills related to an increase in SI knowledge and tools application, and also capacities to 
develop empathy with students and communities were the most valued ones; conversely, they expressed that the project barely helped them to develop abilities for interdisciplinary work (see Figure 6 below).

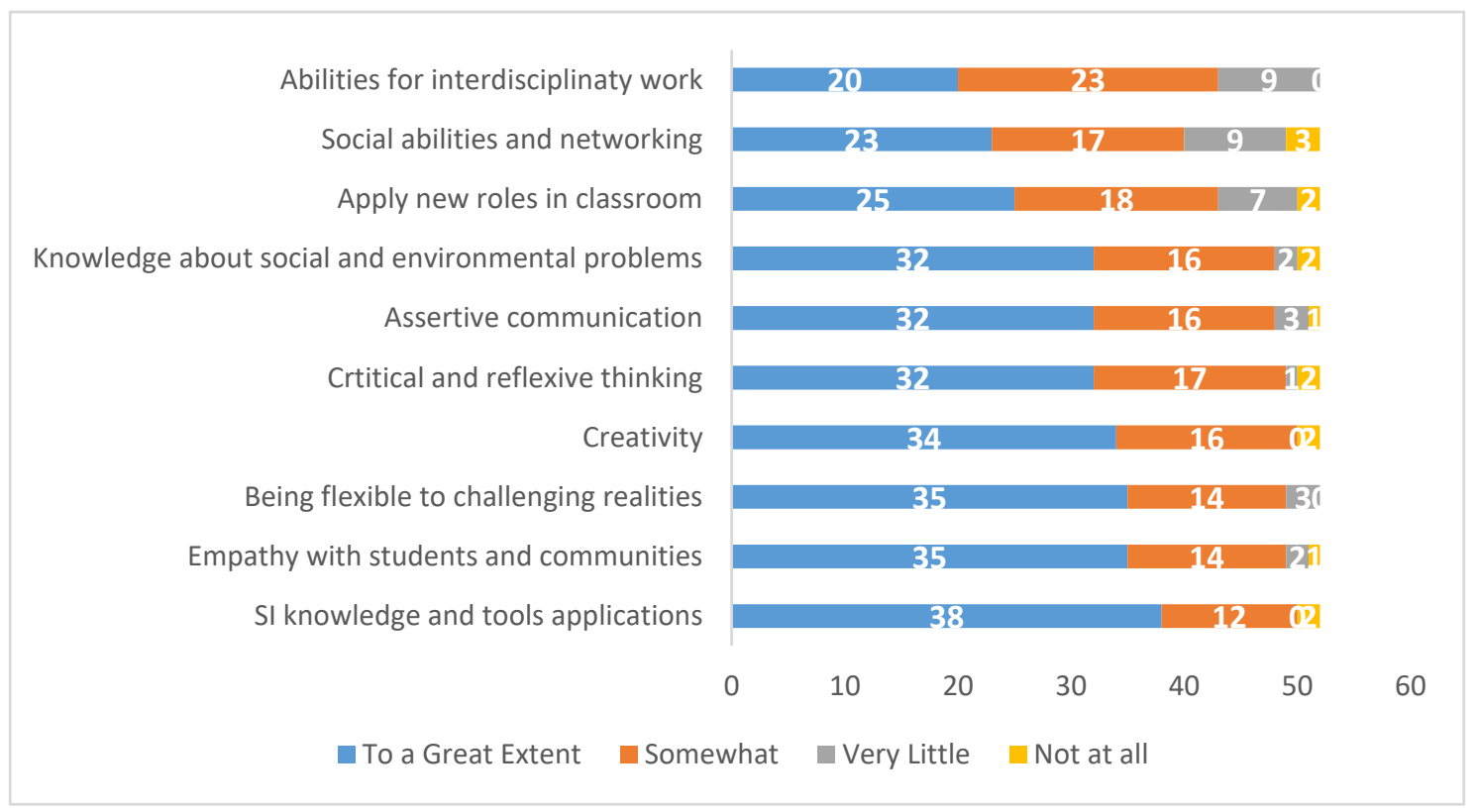

Figure 6. Teachers' skills improvement. Source: Henao and Samoilovich, 2019.

By the same token, information gathered through interviews and focus groups with students revealed that they considered the project helped them acquire skills for developing empathy towards different realities and problems as well as understanding theoretical content through practice. However, they stated that they had few opportunities to improve researching skills (see Figure 7 below).

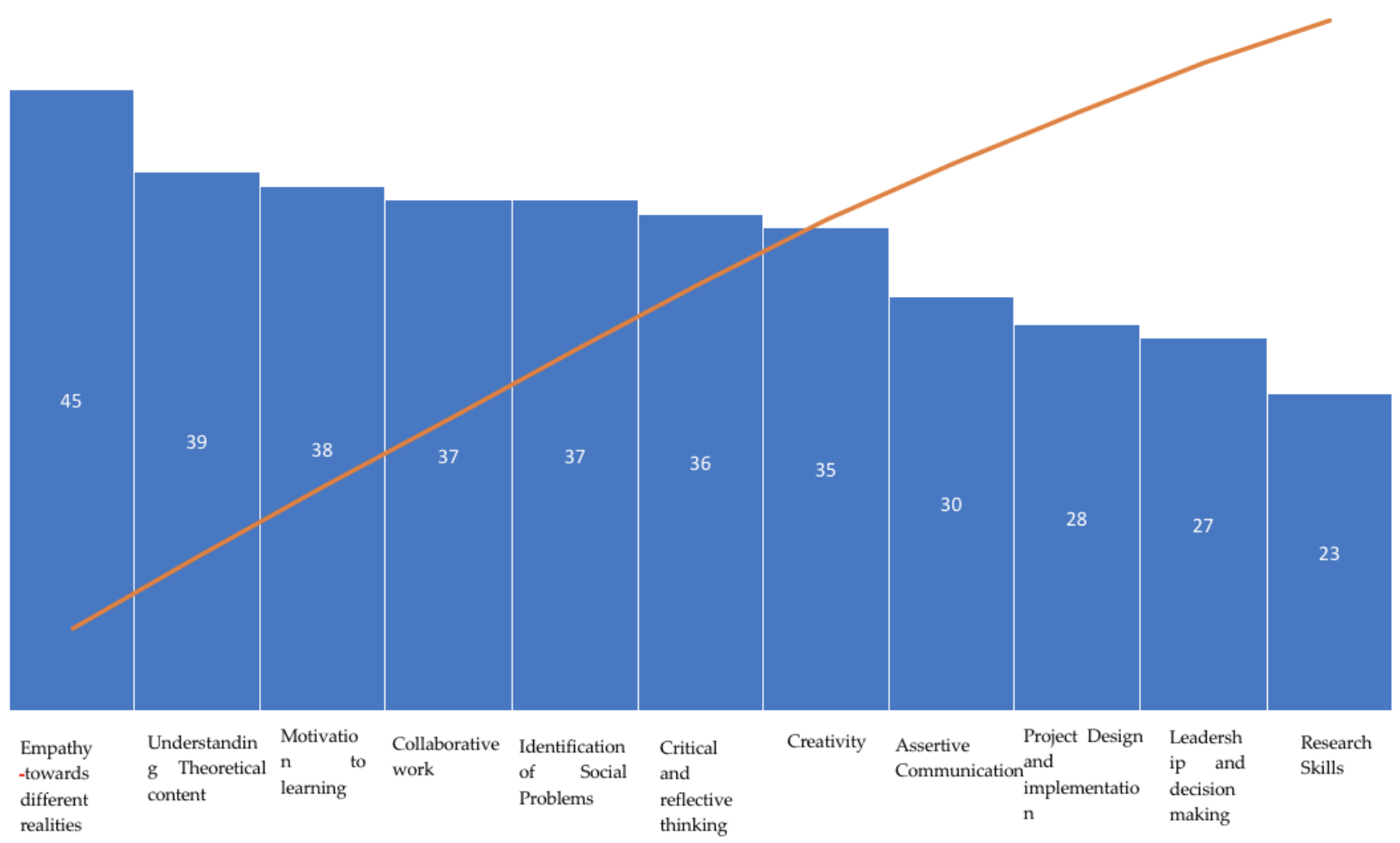

Figure 7. Students' skills improvement. Source: Henao and Samoilovich, 2019. 
Some quotations from teachers and students gathered in the interviews and the focus groups support the data as seen in the following:

“... competencies were well written and they help you focus the project towards the future..." (Teacher participating in the project).

"The tools were good and understandable. It is difficult to know which one to select." (Teacher participating in the project).

"Social innovation was not unknown to me. However, thanks to the project, I was able to delve into the concept and distinguish between different approaches" (Student participating in the project).

"Students4Change provided me with a platform in which I could have access to similar projects worldwide..." (Student participating in the project).

"Students4Change gave us the opportunity to learn from each other and to strengthen the links between students, teachers from different backgrounds, countries and contexts" (Teacher participating in the project).

On the other hand, among the weaknesses of the programme, students and academics agreed that lack of time to implement the model, bureaucracy, and a lack of awareness of the topic were the main barriers for the programme.

"At the beginning of the course, some students considered the subject to be a Maria (an easy, less-important subject)". (Teacher participating in the project).

"... At the beginning of the project, it was really difficult to put the different knowledge together and focus on a specific goal". (Teacher participating in the project).

(B) Research activities.

In the field of research, the Students4Change project promoted the development of research activities related to the experiences and learning from the implementation of the pilot projects. The project created two specific moments in order to facilitate the drafting of articles, papers, or academic presentations: (A) The Students and Teachers Meeting of the Students4Change Project held in April 2019 in Bogota (Colombia). Through an internal call for papers, teachers were encouraged to write articles that would showcase the lessons learned, as well as the barriers and drivers of their experience. A total of 26 articles were submitted by professors from the participating universities, which were grouped into four categories: environmental protection and food security, health and well-being, equity and inclusion, and education and inclusion. (B) Students4Change Academic Colloquium, held in August 2019 in Mexico City (Mexico). An open call for papers was launched within the universities participating in the project. Three were the categories of this call: health, environment, and food security; inclusion and education; and equity and development. Of the 15 papers selected, 11 came from Latin American institutions participating in the project, 3 from European universities, and 1 from an expert in the field of social innovation in Mexico (see Table 4 below).

Table 4. Academic articles presented within the framework of the project.

\begin{tabular}{|c|c|c|c|c|c|c|c|c|c|c|c|}
\hline Meeting & $\begin{array}{l}\text { Puc } \\
\text { Rio }\end{array}$ & $\begin{array}{c}\text { Puc Rio } \\
\text { do Sul }\end{array}$ & U. Caldas & Uniminuto & $\begin{array}{c}\text { U. } \\
\text { Costa Rica }\end{array}$ & $\begin{array}{c}\text { Inst. } \\
\text { Tecnologico } \\
\text { Costa Rica }\end{array}$ & U. Talca & $\begin{array}{c}\text { Puc. } \\
\text { Valparaiso }\end{array}$ & $\begin{array}{c}\text { U. } \\
\text { Colima }\end{array}$ & $\begin{array}{c}\text { TEC } \\
\text { Monterrey }\end{array}$ & Total \\
\hline Bogota & 1 & 3 & 2 & 4 & 3 & 3 & 2 & 3 & 2 & 3 & 28 \\
\hline Mexico & 0 & 1 & 0 & 1 & 0 & 2 & 0 & 1 & 1 & 5 & 11 \\
\hline Total & 1 & 4 & 2 & 5 & 3 & 5 & 2 & 4 & 3 & 8 & 37 \\
\hline
\end{tabular}

Source: authors' elaboration.

As shown in Table 4 above, academic staff from the Tecnológico de Monterrey submitted eight articles, followed by the Uniminuto university and the Technological Institute of Costa 
Rica with five. A relevant fact is that all the universities presented academic articles either at the Bogota or the Mexico meeting.

The wide range of topics covered in the articles is worth noting. These, within each of the categories, covered diverse aspects-from a practical application in the field of cancer cell research by students of one of the pilot courses, to the innovative experience of midwives in rural communities in Chiapas.

According to the data gathered, 17 articles correspond to the education and inclusion category; 8 to health and well-being and equity and inclusion; and, finally, 4 articles belong to environmental protection and food security (see Figure 8 below).

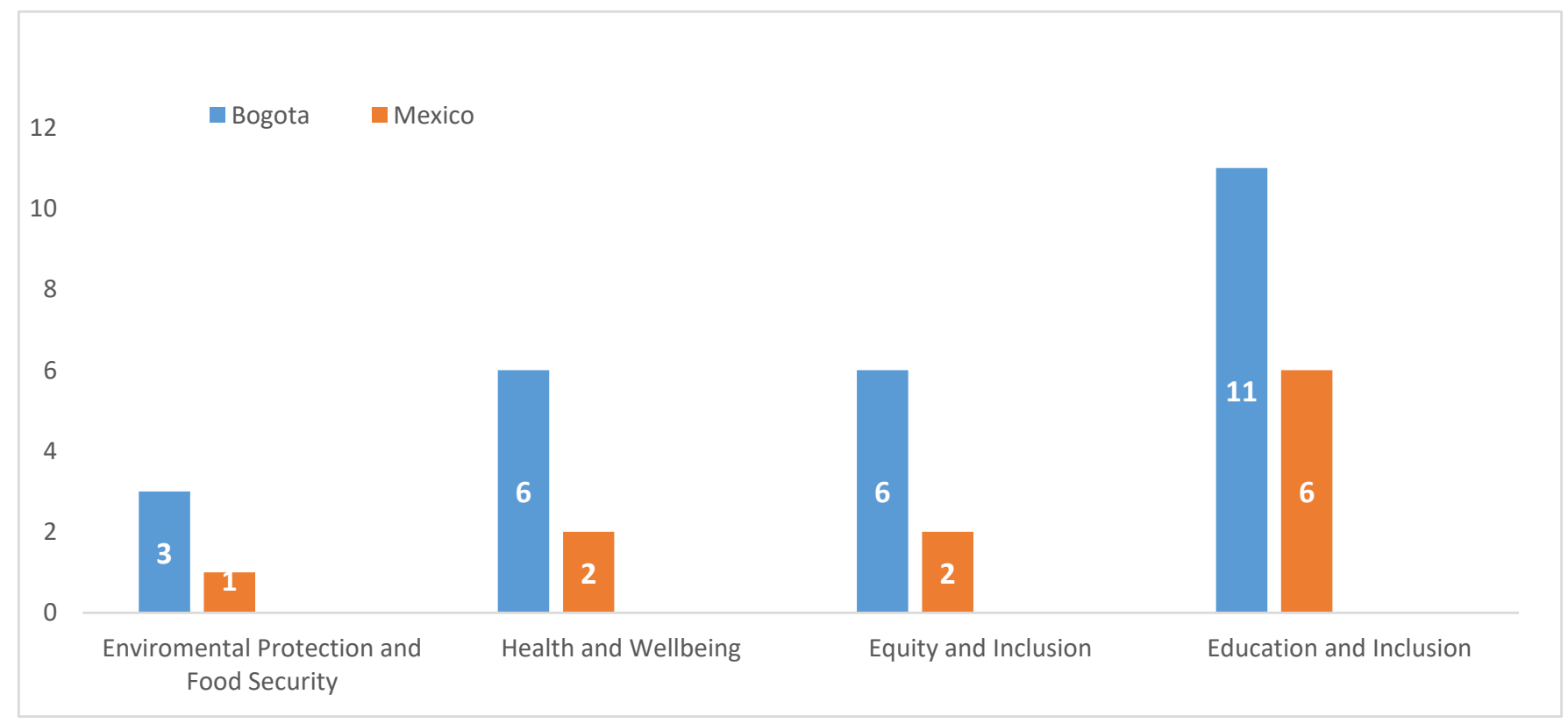

Figure 8. Distribution of articles per category. Source: authors' elaboration.

In this way, the social problems are addressed from different perspectives, but without losing sight of the fact that SI and SE are the categories that guide the systemic changes in the different communities where each and every one of them takes place. The complete list of the articles presented in both meetings can be found in Supplementary Files S5 and S6.

In addition, the S4C project has developed capacities and motivation among the academic staff of the participating universities to carry out further research in these fields. Clear evidence of this is the production of additional articles and research projects outside the scope of S4C, notably Uniminuto, which conducted more in-depth research in one of the pilot projects (Cultivarte), and PUC Rio, which has published an e-book with a compilation of articles on the $\mathrm{S} 4 \mathrm{C}$ project [31].

(C) Community outreach activities.

Data gathered by both the internal and external evaluation corroborate that SI courses at each institution resulted in student projects. Each university selected the most outstanding student projects, which were presented at the Bogota meeting in April 2018. Thus, students from the 10 Latin American universities had the opportunity to exchange knowledge and best practices with their peers through a poster exhibition session run at the meeting. A total of 45 projects were submitted, responding to diverse themes ranging from projects proposing innovative initiatives for organisational change to those addressing specific needs of vulnerable groups or promoting environmental protection. Supplementary File S4 shows the list of pilot projects including the topic and description.

In all Latin American universities, students developed entrepreneurship or social innovation projects. As shown in the Table 5, Uniminuto was the university that presented 
the largest number of projects, although this may have been due to the fact that they hosted the event.

Table 5. Academic articles presented within the framework of the project.

\begin{tabular}{ccccccccc}
\hline & $\begin{array}{c}\text { Puc- } \\
\text { Río }\end{array}$ & $\begin{array}{c}\text { Puc Rio } \\
\text { do Sul }\end{array}$ & U. Caldas & Uniminuto & $\begin{array}{c}\text { U. Costa } \\
\text { Rica }\end{array}$ & $\begin{array}{c}\text { Inst. } \\
\text { Tecnológico } \\
\text { Costa Rica }\end{array}$ & $\begin{array}{c}\text { U. } \\
\text { Talca }\end{array}$ & $\begin{array}{c}\text { Puc. } \\
\text { Valparaíso } \\
\text { Colima }\end{array}$ \\
\hline Bogota & 4 & 4 & 3 & 8 & 4 & 4 & 5 & 4 \\
\hline
\end{tabular}

It is noteworthy that many projects continued their development after the end of the academic semester specifically, as reported by the Columbus Association [34], "around $63.5 \%$ of the surveyed academic staff confirmed that some students took their project to a further level".

Finally, as regards community engagement, interviews and focus groups with students acknowledged that the pilot projects allowed them to have closer connections with the communities, and therefore they were able to put theory into practice by addressing real social problems. Some actors were involved from the beginning of the project encouraging students to frame the problem, some others received knowledge transfer from the students while many others participated throughout the whole pilot project [34]. One of the great strengths of the project has been precisely the possibility of forging closer ties with the communities; many voices support this idea, for example:

"... real social change could be achieved if we look to work together with the communities and other partners. Collaborative and creative forms of work are essential here". (Teacher participating in the project).

" ... I would like to continue with this project after the pilot. Having direct connections with the communities led me to change the way I looked at the actual problems". (Students participating in the project).

"... social innovation is very enriching. It allows you to take knowledge to the field". (Student participating in the project).

"... we understand that we are not going to solve the problems of the world but the social innovation approach helps us get closer to real problems and communities" (Student participating in the project).

Although many pilots involved several kinds of actors, this is one of the dimensions that will require more attention and should be strengthened in the future.

\section{Discussion}

Considering the aforementioned information, we find that there is no doubt that SI in the context of Latin American universities has experienced a great boost in recent years, and HEIs have even been driving forces in the development of SIs in the region, as pointed out by Domanski, et al. [9]. Despite this, there are still many areas of opportunity for Latin American universities to become key actors in building up a real ecosystem of SI [35] in the region.

Building on these and other findings from the project itself, the following paragraphs introduce some reflections on enablers and constraints for SI in HEIs.

At the beginning of the project, different universities used different definitions and approaches regarding SI and SE. Thus, the terms were often used interchangeably to refer to other concepts such as social entrepreneurship, social responsibility, or social economy. In support to the academic literature, results from the project have revealed that knowledge about SI was still fragmented and different approaches to its concept were predominant within both Latin American and European HEIs [16]. This lack of clarity was also reflected in the absence of a consensus on the content to be taught or the competences to be developed [36], which led us to consider it as a clear deficiency for the integration of SI in academia, backing up the existing literature on the topic. 
Therefore, efforts were made to fill this gap, resulting in one of the main contributions of the project which, through collaborative work, developed a broad and flexible conceptualisation of social innovation, including an open and extensive definition of the concept, a clear identification of the competences required to create a social innovation-friendly environment, and a methodological proposal tailored to the contextual and specific needs of each HEI.

The proposal of the Students4Change project rests on the certainty that in order to offer social value, HEIs must focus their efforts on competence-based education, which implies that the student is able to distinguish different issues and look for context-based solutions that can have a real impact [37].

In this sense, our findings suggest that the Students4Change project has demonstrated that having a common language around SI and SE must be considered as a key initial condition for framing an academic syllabus on SI in HEIs of Latin America, and also that this approach should be broad enough to respond to "each identity, culture and specific ecosystem", an issue that is also highlighted by professor Richard Hazenberg in his studies on SI in HEIs of the East and Southeast Asia [38].

Students4Change has enabled a link to be established between societal challenges, 21st century skills, consortia of HEIs, businesses, and communities. The project has provided a portfolio of at least 59 innovative curricula that have been shared among the 10 Latin American institutions. Transversal competences, such as problem identification and solving, cooperative and communicative skills, and impact assessment, occupy a central place in the innovative projects that students from the universities have developed. As is the case with innovative pedagogical methods such as the flipped learning, SI learning increases student motivation, boosts collaboration and academic performance, and strengthens students' links with the community [39].

These 10 HEIs have promoted the full-scale implementation of a common syllabus on SI by sharing their experience and supporting each other, which has contributed to a collaborative culture within and between higher education institutions in the region, as evidenced by the new projects which have been running between many members of the project.

In addition, the curriculum and training courses provided an innovative and supportive educational resource for teachers, youths, and academic staff, and thus, despite numerous barriers, HEIs were able to integrate the curriculum into their programmes. In this regard, the most important challenge for universities is to overcome the aversion to change as well as to guarantee the sustainability of the implementation of the curriculum after the life of the project [40].

In short, evidence from Students4Change suggests that although HEIs in Latin America have developed different educational responses in relation to SI, there is still a widespread feeling today that there is a need to formalise a programme specifically designed to promote SI and SE and to train universities in that endeavour. Moreover, in order to incorporate SI within universities, backing up the idea of López-Belmonte et al. [41], specific training programs on SI and SE are needed not just for students but also for teachers. Teachers and students should acquire competences to, firstly, interpret a social problem; secondly, assimilate or transform the interpretation, integrating the knowledge into prototypes, products, services, or methods that provide answers to the problem that we want to solve; and thirdly, experiment with and transfer solutions and evaluate their impact [42].

Research into SI in the Latin American region has been mostly focused on studying the dynamics related to the social economy and social entrepreneurship, thus leaving a gap in the analysis of other dimensions related to the concept. The Students4Change project has contributed towards filling this gap by promoting and opening up research in participating institutions. It has also confirmed that university-based SI initiatives in Latin America have moved from being a niche to a mainstream concept [43], and therefore this as a field of research has also experienced a significant evolution. Despite efforts, research in this field 
in the region is still scarce and siloed, as the project has confirmed. There is still a latent need for conducting multidisciplinary and transdisciplinary research which helps bridge the divide between knowledge generated by academia and practical exercises developed in society.

It is therefore advisable that Latin American universities take an active role in compiling, systematising, analysing, and disseminating the different approaches to social innovation led by universities in the region, as well as carrying out comparative studies to identify which aspects of these practices can be scalable and which cannot. Thus, the results of the project have shown us that a big challenge for Latin American HEIs is to establish linkages and learning opportunities which can have a clear potential to develop a SI ecosystem.

Alongside the two traditional missions of teaching and research, a third mission linked to the contribution of universities to local development and the well-being of communities is increasingly gaining momentum in academia [44]. Within this framework, universities are encouraged to foster innovation, in general, but also SI, in particular, as a way to contribute towards the development of human capital. Although, as with the terms SI and SE, there is no unanimity within academia about what the third mission is and what activities it involves, for the purpose of this article, we endorse the approach of Benneworth, et al. for whom the third mission would be represented by engagement activities that "take place within the processes of knowledge creation and dissemination and in which both universities and external actors are involved" [44].

In this sense, establishing long-term relationships with actors from different societal sectors is seen as one of the key factors for the successful work of Higher Education Institutions in the field of social innovation. Scholars such as Schröder and Krüger point out the influence that the network of actors has on the failure or success of social innovations in academia [10]. Students4Change has demonstrated that involving local communities in SI research and practice initiatives, making visible the benefits of the third mission, within the universities and building partnerships with them, have proven to be important factors for the successful and sustainable implementation of social innovation courses in the Latin American partner universities.

Lastly, many of the participating HEIs have developed added valued activities such as SI labs, incubators, or projects and they have conducted research in topics such as social entrepreneurship, supported by specialised facilities. The "state of the art" and other documents produced within the project reveal the existence of a two-speed process in the integration of SI in Latin American universities and three types of developments in the field. Some universities have developed basic and specialised courses, conducted research on specific topics, or developed social innovation incubators and labs to implement initiatives with local communities, while in other universities, the social innovation approach is still premature [45]. Regarding the development of teaching programmes, research, and community-based initiatives, the analysis of data leads us to distinguish three types of universities. A first group made up of universities with experience in the field of SI and $\mathrm{SE}$; a second group, with a long background in the field of SE but little experience in SI (mostly linked to welfare interventions); and finally, a third group made up of those universities which, prior to the project, declared that they had not developed SI initiatives (although they had implemented social innovation initiatives without being aware of it) (see Supplementary File S1).

All in all, linked to the above and according to the literature in the field, many social innovation systems identified in the Latin American HEIs find themselves at the early stages of formation, with very limited SI capabilities, as well as underdeveloped networks and collaborations between different actors of the social innovation ecosystem. Moreover, technological and market-oriented innovation still drives the field of innovation in Latin American HEIs [46]. This led us to define that while SE is well stablishing in the region, the challenge is in how to integrate SI into the universities. Similar limitations were found by Hazenberg in his research, who emphasised the need to, firstly, foster 
relational universities [47] that place collaboration as a strategic element; secondly, create knowledge networks and alliances between students, teachers, and communities; and thirdly, encourage the creation of policy frameworks that foster SI in HEIs [48].

In Table 6, we have summarised the strengths and weaknesses for the integration of SI and SE, which have become apparent through this article.

Table 6. Summarised strengths and weaknesses for integrating SI and SI within participating HEIs in the project.

\begin{tabular}{lll}
\hline \multicolumn{1}{c}{ Strengths } & \multicolumn{1}{c}{ Weaknesses } \\
\hline - $\quad \begin{array}{l}\text { Co-curriculum: collaborative work } \\
\text { - } \quad \begin{array}{l}\text { Common understanding and approaches } \\
\text { on challenges }\end{array}\end{array}$ & $\begin{array}{l}\text { Resource constraints (internal and external) } \\
\text { Competitiveness } \\
\text { - } \quad \text { Motivations }\end{array}$ & $\begin{array}{l}\text { Social innovation is new for many teachers } \\
\text { Bureaucracy }\end{array}$ \\
- Student demand: interest and demand by & Novelty of the field in the university \\
students for new courses and & Time constraints: social innovation is not an \\
opportunities in the social innovation & issue for a 6-month programme Faculty buy-in \\
field manifested in pro-active & Clear leadership \\
participation in competitions and & A clear policy on social innovation \\
knowledge exchange activities & Links with communities and stakeholders \\
Need to attract and retain students & Multidisciplinary and \\
- Support of academic leaders & trans-disciplinary research \\
Peer exchange & \\
\hline Source: authors' elaboration. &
\end{tabular}

This research hopes to outline possible changes that can be applied across the HEI sector in Latin America to foster the growth of social innovation research, curriculum development, and knowledge transfer to local communities.

Thus, this paper is interesting because it will contribute to identifying the main levers of change, strengths, and challenges that Latin American universities face in order to institutionalise SI and SE in their contexts and will also contribute to strengthening the momentum of a SI ecosystem in the region. The research also provides a comprehensive analysis of existing SI activities in research, teaching, and community engagement led by those HEIs. Thus, this research is of great interest to researchers who want to develop future lines of research into designing proposals for strengthening curricular models through the integration of new approaches such as social innovation with social impact, as well as for practitioners who seek to deploy effective strategies within local communities.

\subsection{Limitations of the Research}

Since every research project has its limitations, this one is no exception. On the basis of analysed experience, we would highlight the following limitations:

1. The article is limited solely to the study of social innovation in 10 Latin American universities in the five countries participating in the Students4Change project.

2. The way in which social innovation is integrated into each academic syllabus differs from country to country, and these differences have not been analysed in the research. Therefore, they may well be the subject of further research. Obviously, this would need to be conducted on a smaller scale, and multiple case studies appear to be an appropriate method.

The data cover a very limited period of time, in all cases corresponding only to the implementation of social innovation in one academic semester. This circumstance has made it possible to identify results in the short term and to outline possible results in the medium term but has made it difficult to obtain results in the long term. Therefore, it has been hard to measure the long-term impact and to analyse the transformative impact of HEIs as active actors of systemic change. In fact, this identification has only been possible in the case of those Latin American HEIs with previous experience in social innovation. 
These limitations lead us to recognise that the results offered in this paper should be considered as insights.

\subsection{Future Lines of Research}

Taking into account the limitations outlined above, in terms of future lines of research, we found that the results of the Students4Change project are a good starting point for further empirical research, specifically:

Firstly, a future line of research should focus on deepening the analysis of the meaning of social innovation and social entrepreneurship within the institutional framework of Latin American universities by conducting comparative studies of these approaches in different countries. Some possible research questions could revolve around seeking answers to questions such as: What are the roles of academia in social innovation practices? What geographical differences exist? among others.

Secondly, it would be advisable to carry out a transversal and solid analysis of how social innovation is inserted into the curricula of the different disciplines within universities. In this sense, questions which may guide the research are, for example, What are the new ways of framing, doing, organising, and learning that are taking hold? How do institutional environments enable or hinder behaviour? How can universities shape the social innovation ecosystem in general?

Thirdly, stream research could be used to conduct a strong line of research into understanding and identifying the impacts on students of engaging in social innovation during their studies on the basis of questions such as: What is the impact of research and teaching on students during and after their studies?

Fourthly, a more comprehensive comparative country-based analysis of the social impact of social innovation initiatives on HEIs and local communities is advisable. A line of research in this direction could explore the relationships between the HEIs and the stakeholders focusing on the differences between countries; for example, exploring how academia can effectively engage with communities in ways that foster empowerment, or to what extent HEIs' work with communities is in line with their mission statements and organisational intentions.

Finally, and on the basis of the two previous points, we strongly recommend that research be carried out into designing a model of indicators to measure the impact of social innovation activities led by universities and to measure how and to what extent a fruitful combination of academia and social innovation practice can lead to a transformative impact. In the same token, there is an opportunity for universities to set themselves apart and put themselves at the front of the change process around the world by offering proposals to connect social innovation with sustainable development goals (SDGs).

All in all, we would like to stress that in a world of continuous and ongoing transformations, universities must become agents of change and SI is indispensable. The interest generated by the project inside and outside the HEIs participating in the research leads us to believe that interest in SI is growing rapidly and that it will be increasingly integrated into the curricula of Latin American universities.

\section{Conclusions}

According to the academic literature, Latin American universities, as active agents of local development, have made a great effort to integrate SI into their activities. Backing up this idea, lessons learned from the project lead us to emphasise six aspects:

1. To observe that contemporary global challenges demand changes in mindsets and behaviours, and that, in this endeavour, universities are becoming central actors and social innovation is gaining momentum as a useful tool to face these challenges.

2. To recognise that, although it is important to generate common understandings, objectives, and strategies to integrate SI, the "one size-fits-all" [48] approach is not valid in all cases, as the way in which we understand, deploy, and approach it responds to the specific characteristics of local contexts. 
3. To acknowledge that further and more diverse cross-sectoral and transdisciplinary research is needed to deepen the understanding of social innovation and to measure the social impact of the initiatives and, therefore, the fact that Latin American HEIs face the great challenge of turning SI into a structured academic discipline.

4. To reflect on their transformative role as agents of change and thus strengthen actions to integrate social innovation holistically into their three missions [16] by functioning properly both in a single and collective way.

5. To firmly anchor SI into the strategy of the HEIs. Universities have to strategically manage SI, and to do this they have to incorporate social innovation in university policies and strategic plans, allocating more resources (technical, financial, and human) to ensure its sustainability.

6. To be aware that if they really want to introduce SI into a new academic curriculum, universities should undertake a transformative process that allows them to leave aside the red tape which framed the institution and to think critically about how to redesign the way we learn to foster activities which contribute to systems change.

In short, Latin American HEIs are moving from an early stage of development and implementation to a stage of growth, evolution, and institutionalisation. Within the Students4Change project, not only has each HEI developed a proposal to introduce SI and SE into the curricula, but also they have promoted this approach for driving social change within their local communities through research, training, and knowledge transfer. However, although promoting connections between universities and societies is beneficial for both HIEs and communities, incorporating a SI approach is not a straightforward endeavour. Indeed, there are still considerable gaps, as well as external and internal barriers to embedding social innovation in academia [49].

Supplementary Materials: The following are available online at https:/ / www.mdpi.com/article/10 $.3390 /$ su13105378/s1.

Author Contributions: Conceptualisation, A.U., I.G., and X.B.; investigation, I.G.; writing-original draft preparation, I.G. and X.B.; methodology I.G. and X.B.; writing-review and editing, I.G.; supervision, A.U.; project administration, I.G. All authors have read and agreed to the published version of the manuscript.

Funding: This research was co-funded by the Erasmus Plus Program of the European Union under Key Action 2 with the following reference number: 2 574133-EPP-1-2016-1-MX-EPPKA2-CBHE-J.

Institutional Review Board Statement: Not applicable.

Informed Consent Statement: Not applicable.

Data Availability Statement: The data presented in this study are available within the article and Supplementary Materials and from the corresponding author.

Acknowledgments: The authors would like to thank the Erasmus Plus Programme for funding the project, as well as all the members of the consortium (the Technological University of Monterrey, the University of Colima, the University of Costa Rica, the Technological University of Costa Rica, Uniminuto, the University of Caldas, the PUC Valparaiso, the University of Talca, the PUC Rio, the PUC Rio do Sul, the University of Aveiro, the Polytechnical University of Valencia, the University of Grenoble, and the University of Dortmund), as well as the Columbus Foundation that led the external evaluation of the project. We would like to acknowledge all the participating teachers, students, and academic staff from the Latin American HEIs that have participated in this project.

Conflicts of Interest: The authors declared no conflict of interest.

\section{References}

1. Avelino, F.; Wittmayer, J.M.; Kemp, R.; Haxeltine, A. Game-changers and transformative social innovations. Ecol. Soc. $2017,22,41$. [CrossRef]

2. European Commission. Guide to Social Innovation; European Commission: Brussels, Belgium, 2013.

3. Bureau of European Policies. Social Innovation: A Decade of Changes; Publication Office of the European Union: Luxembourg, 2014. 
4. Howaldt, J.; Bultzin, A.; Domanski, D.; Kaletka, C. Theoretical Approaches to Social Innovation: A Critical Literature Review. SI-DRIVE Deliverable 1.1; TU Dortmund University: Dortmund, Germany, 2014.

5. Moulaert, F.; Mehmood, A.; MacCallum, D.; Leubolt, B. Social Innovation as a Trigger for Transformations: The Role of Research; European Commission: Luxembourg, 2017.

6. Domanski, D.; Howaldt, J.; Schröder, A. Social Innovation in Latin America. J. Hum. Dev. Capab. 2016, 18, 307-312. [CrossRef]

7. Ayob, N.; Teasdale, S.; Fagan, K. How Social Innovation 'Came to Be': Tracing the evolution of a contested concept. J. Soc. Policy 2016, 45, 635-653. [CrossRef]

8. Rey de Marulanda, N.; Tancredi, F. De la Innovación Social a la Política Pública: Historias de Éxito en América Latina y el Caribe; CEPAL: Santiago, Chile, 2010.

9. Domanski, D.; Monge, N.; Quitiaquez, G. Introducción: Innovación Social en América Latina. In Innovación Social en América Latina; Domanski, D., Monge, N., Quitiaquez, G., Rocha, D., Eds.; Corporación Universitaria Minuto de Dios: Bogota, Colombia, 2016; Available online: http://umd.uniminuto.edu/documents/1242125/7107898/Innovaci\%C3\%B3nSocial_Latinoamerica. pdf/18b5de7a-0ae8-4aa0-be18-a3c22d4762e1?version=1.0 (accessed on 28 April 2021).

10. Schröder, A.; Kruger, D. Social Innovation as a Driver for New Educational Practices: Modernising, Repairing and Transforming the Education System. Sustainability 2019, 11, 1070. [CrossRef]

11. Blass, E.; Hayward, P. Innovation in higher education; will there be a role for the "academy/university" in 2025? Eur. J. Futures Res. 2014, 2, 41. [CrossRef]

12. Alexis, M.; Karenia, C. Universidad latinoamericana: Ciencia, tecnología e innovación para afrontar los imperativos de la sustentabilidad. In La Investigación Científica y Tecnológica como Motores del Desarrollo Humano, Social y Económico para América Latina y el Caribe; pp. 129-181. Available online: https:/ / www.iesalc.unesco.org/2019/07/17/coleccion-cres-2018-la-investigacioncientifica-y-tecnologica-y-la-innovacion-como-motores-del-desarrollo-humano-social-y-economico-para-america-latina-y-elcaribe/ (accessed on 28 April 2021).

13. UNESCO. Conferencia Mundial Sobre Educación Superior en el Siglo XXI: Visión y Acción; Comunicado; UNESCO: Paris, France, 1999.

14. UNESCO. Conferencia Mundial Sobre la Educación Superior-2009: La Nueva Dinámica de la Educación Superior y la Investigación Para el Cambio Social y el Desarrollo; Comunicado; UNESCO: Paris, France, 2010; p. 17.

15. Ziegler, R. Social Innovation and the Capability Approach. In Atlas of Social Innovation. New Practices for a Better Future; Howaldt, J., Kaletka, C., Schröder, A., Zirngiebl, M., Eds.; TU Dortmund University: Dortmund, Germany, 2018; p. 245.

16. Domanski, D.; Majewski, A.M.; Jürgen, H. Social Innovation as a Chance and a Challenge for Higher Education Institutions. In Atlas of Social Innovation: New Practices for a Better Future; Howaldt, J., Kaletka, C., Schröder, A., Zirngiebl, M., Eds.; SI-DRIVE Deliverable No 12.6; TU Dortmund University: Dortmund, Germany, 2018; pp. 50-53. Available online: https://www.socialinnovationatlas.net/fileadmin/PDF/einzeln/01_SI-Landscape_Global_Trends/01_06_SI-and-theCapability-Approach_Ziegler.pdf (accessed on 28 April 2021).

17. Altbach, P. The Complex Roles os Universities in the Period of Globalization. In Higher Education in the World 3: Higher Education: New Challenges and Emerging Roles for Human and Social Development; Palgrave Macmillan: London, UK, 2008 ; pp. 5-19.

18. Maassen, P.; Andreadakis, Z.; Gulbrandsen, M.; Stensaker, B. Growing focus on the universities' third mission: The changing place of universities in society worldwide. In The Place of Universities in Society; Körber-Stiftung: Hamburg, Germany, 2019.

19. Gordon, A.; Becerra, L.; Fressoli, M. Potentialities and constraints in the relation between social innovation and public policies: Some lessons from South America. Ecol. Soc. 2017, 22, 2. [CrossRef]

20. Eichler, G.; Schwarz, E. What Sustainable Development Goals Do Social Innovations Address? A systemic Review and Content Analysis of Social Innovation Literature. Sustainability 2019, 11, 522. [CrossRef]

21. Moulaert, F.; MacCallum, D.; Mehmood, A.; Hamdouch, A. The International Handbook on Social Innovation. Collective Action, Social Learning and Transdisciplinary Research; Edward Elgar Publishing: Cheltenham, UK, 2013.

22. Mulgan, G. Social Innovation: The Last and Next Decade. In Atlas of Social Innovation: New Practices for a Better Futur; Howaldt, J., Kaletka, C., Schröder, A., Zirngiebl, M., Eds.; SI-Drive Deliverable No. 12.6; TU Dortmund University: Dortmund, Germany, 2018; pp. 194-197. Available online: https://www.socialinnovationatlas.net/fileadmin/PDF/einzeln/04_Future-Challengesand-Infrastructures /04_01_SI-the-last-and-next-decade_Mulgan.pdf (accessed on 28 April 2021).

23. Galego, D.; Moulaert, F.; Brans, M.; Santinha, G. Social Innovation and Governance: A scoping review. Eur. J. Soc. Sci. Res. 2021, 1-26. [CrossRef]

24. Didriksson, A. La nueva agenda de transformación de la educación superior en América Latina. Perfíles Educ. 2012, 34, 184-203. [CrossRef]

25. Didriksson, A.; Acosta, A.; Aponte, E.; Larrea, E.; Leite, D.; Orozco, L.E.; Moreno, C.I. University Social Engagement: Current Trends in Latin America and the Caribbean at Global/Local Universities; Global University Network for Innovation GUNI: Girona, Spain, 2017; pp. 472-491. Available online: http:/ / www.guninetwork.org/articles/university-social-engagement-current-trends-latinamerica-and-caribbean-globallocal (accessed on 28 April 2021).

26. Global University Network for Innovation GUNI. Higher Education in the World 6: Towards a Socially Responsible University: Balancing the Global with the Local; Global University Network for Innovation GUNI: Girona, Spain, 2017.

27. Anderson, T.; Curtis, A.; Wittig, C.; Definition and Theory in Social Innovation. The theory of social innovation and international approaches. In Zentrum für Soziale Innovation (ZSI). Discussion Paper n. 33; Vienna, Austria,, 2015; Available online: https: //www.zsi.at/en/object/publication/3641 (accessed on 28 April 2021). 
28. University of Aveiro; University of the Basque Country; Ashoka. Social Innovation and Social Entrepreneurship in Higher Education Institutions; Instituto Tecnológico y de Estudios Superiores de Monterrey: Mexico City, Mexico, 2019; pp. 15-44. Available online: https:/ /f7b10733-f12f-4d47-94e3-a4f3d68651f0.filesusr.com/ugd/2725b7_1a77f26d39704c3489cfdf808fa03a7c.pdf (accessed on 28 April 2021).

29. Fundación Ecología y Desarrollo; Multilateral Investment Fund. Study of Social Entrepreneurship and Innovation Ecosystems in the Latin American; Banco Interamericano de Desarrollo: Washington, DC, USA, 2016.

30. Domanski, D.; Kaletka, C. La Investigación en Innovación Social en la Unión Europea y la Experiencia de la TU Dortmund University. In Innovación Social en América Latina; Domanski, D., Monge, N., Quitiaquez, G., Rocha, D., Eds.; Corporación Universitaria Minuto de Dios: Bogota, Colombia, 2016. Available online: https://eldorado.tu-dortmund.de/bitstream/2003/358 42/1/La_investigaci\%c3\%b3n_en_Innovaci\%c3\%b3n\%20_Social_en_la_Uni\%c3\%b3n_Europea_TU_Dortmund.pdf (accessed on 28 April 2021).

31. Student4Change Project. 2019. Available online: https://www.uestudents4change.org/home (accessed on 19 February 2021).

32. Galego, D.; Amorim, M.; Ferreira, M.; Soto, W.; Carrasco, G. Embedding Social Innovation in Latin America Academic Curriculum. In Proceedings of the 4th International Conference on Higher Education Advances, Valencia, Spain, 20-22 June 2018; pp. $1239-1247$. Available online: https:/ / riunet.upv.es/handle/10251/109625 (accessed on 28 April 2021).

33. Benneworth, P.; Cunha, J. Universities' contributions to social innovation: Reflections in theory \& practice. Eur. J. Innov. Manag. 2015, 18, 508-527. [CrossRef]

34. Henao, K.; Samolovich, D. External Evaluation Final Report; Internal Report; Columbus Association: Columbus, OH, USA, 2019.

35. Domanski, D.; Kaletka, C. Social Innovation Ecosystems. In Atlas of Social Innovation. New Practices for a Better Future; Howaldt, J., Kaletka, C., Schröder, A., Zirngiebl, M., Eds.; SI-DRIVE Deliverable No 12.6; TU Dortmund University: Dortmund, Germany, 2018; pp. 208-211. Available online: https://www.socialinnovationatlas.net/fileadmin/PDF/einzeln/04_Future-Challengesand-Infrastructures/04_05_SI-Ecosystems_Domanski-Kaletka.pdf (accessed on 28 April 2021).

36. Technische Universität Dortmund; Tecnológico de Monterrey. Social Innovation and Entrepreneurship from the Perspective of the Universities. In Social Innovation and Entrepreneurship in Higher Education Institutions; Palavicini, G., Cepeda, I., Eds.; Instituto Tecnológico y de Estudios Superiores de Monterrey: Mexico City, Mexico, 2019; Available online: https: / / f7b10733-f12f-4d47-94 e3-a4f3d68651f0.filesusr.com/ugd/2725b7_1a77f26d39704c3489cfdf808fa03a7c.pdf (accessed on 28 April 2021).

37. Universidad de Aveiro; Universidad del País Vasco; Ashoka. Capítulo 1. Innovación y Emprendimiento Social: Situación Actual. In Innovación y Emprendimiento Social en Instituciones de Educación Superior; Palavicini, G., Cepeda, I., Eds.; Trcnológico de Monterrey: México City, Mexico, 2019; Available online: https:/ f7b10733-f12f-4d47-94e3-a4f3d68651f0.filesusr.com/ugd/2725 b7_1a77f26d39704c3489cfdf808fa03a7c.pdf (accessed on 28 April 2021).

38. British Council. Social Innovation and Higher Education Landscape in East Asia. A Comparative Study. 2020. Available online: https://www.britishcouncil.org/sites/default/files/sihe_-comparative_study_-_final.pdf (accessed on 28 April 2021).

39. Moreno-Guerrero, A.; Soler-Costa, R.; Marín-Marín, J.; López-Belmonte, J. Flipped learning and good teaching practices in secondary education. Comunciar 2021, 29, 68.

40. Kumari, R.; Kwon, K.-S.; Lee, B.-H.; Choi, K. Co-Creation for Social Innovation in the Ecosystem Context: The Role of Higher Educational Institutions. Sustainability 2020, 12, 307. [CrossRef]

41. Belmonte, J.L.; Sánchez, S.P.; Cabrera, A.F.; García, A.M.R. Análisis del desempeño docente en la educación para el emprendimiento en un contexto español. Aula Abierta 2019, 48, 321-330. [CrossRef]

42. Unceta Alfonso. Comunicación y Transferencia en las Innovaciones Sociales. Codificación y Comunidades del Conocimiento. Hist. Comun. Soc. 2014, 19, 763-776.

43. Augenstein., K.; Bachmann, B.; Egermann, M.; Hermelingmeier, V.; Hilger, A.; Jaeger-Erben, M.; Kressler, A.; Lam, D.; Palzkill, A.; Suski, P.; et al. From niche to mainstream: The dilemmas of scaling up sustainable alternatives. GAIA Ecol. Perspect. Sci. Soc. 2020, 29, 143-147. [CrossRef]

44. Benneworth, P.; de Boer, H.; Jongbloed, B. Between good intentions and urgent stakeholder pressures: Institutionalizing the universities' third mission in the Swedish context. Eur. J. High. Educ. 2015, 5, 280-296. [CrossRef]

45. Domanski, D.; Gotting, A.; Janz, S. Support Mechanisms in Social Innovation and Social Entrepreneurship; Internal Report; Deliverable, Students4Change: 2019. Available online: https://f7b10733-f12f-4d47-94e3-a4f3d68651f0.filesusr.com/ugd/2725b7 _eea8c7ad757f42489935fe7d1066bb07.pdf (accessed on 28 April 2021).

46. Ketelhöhn, N.; Ogliasti, E. Introduction: Innovation in Latin America. Acad. Rev. Latinoam. Adminsitración 2013, 26, 12-32. [CrossRef]

47. Castro-Spila, J.; Alfonso, U. The relational university: Social innovaiton and entrepreneurial skills in creative industries. In Dynamics between the Creative Industries, Knowledge Institutions and the Urban Context; Schramme, A., Kooyman, R., Hagoort, G., Eds.; Eburon Academic Press: Delft, The Netherlands, 2014; pp. 192-201.

48. Giuri, P.; Munari, F.; Scandura, A.; Toschi, L. The strategic orientation of universities in knowledge transfer activities. Technol. Forecast. Soc. Chang. 2019, 138, 261-278. [CrossRef]

49. Papi-Thornton, D.; Cubista, J.J. Systems Change in Social Innovation. Stanford Social Innovation Review, 6 May 2019. Available online: https://ssir.org/articles/entry/systems_change_in_social_innovation_education (accessed on 26 April 2021). 